Atıf/Citation: A. INAL, "Lineer hızlandırıcı cihazında (Linak) alınan rölatif doz ölçümlerinde $\leq 3 \mathrm{~mm}$ geometrik hataların yüzde derin doz (\%DD) ve 1 şın profil (IP) parametreleri üzerine etkisi”, Süleyman Demirel Üniversitesi Fen Edebiyat Fakültesi Fen Dergisi, 14(2), 239-247, 2019.

\title{
Lineer Hızlandırıcı Cihazında (Linak) Alınan Rölatif Doz Ölçümlerinde $\leq 3$ mm Geometrik Hataların Yüzde Derin Doz (\%DD) ve Işın Profil (IP) Parametreleri Üzerine Etkisi
}

\author{
Aysun İNAL ${ }^{1 *}$ \\ ${ }^{1}$ Sağlık Bilimleri Üniversitesi, Antalya Eğitim ve Araştırma Hastanesi, Radyasyon Onkolojisi Bölümü, \\ 07070, Antalya, Türkiye \\ *yazışılan yazar e-posta: aysuntoy@yahoo.com
}

(Alınış / Received: 04.07.2019, Kabul / Accepted: 16.08.2019, Yaylmlanma / Published: 30.11.2019)

Özet: Modern lineer hızlandırıcı (Linak), kanserli hastaların tedavisi için yüksek enerjili X ışınları ve elektron demetleri üreten bir cihazdır. Radyasyon tedavisinin temeli madde ve radyasyon arasındaki etkileşime dayanır. Bu nedenle, radyasyon ve madde arasındaki etkileşim, radyasyon fiziği bilimini kanserin klinik tedavisine dönüştürür. Radyoterapide, dozimetrik ölçümler için en temel rölatif değerlendirmeler; X- 1şınının derinliğe bağlı olarak değişimi gösteren yüzde derin doz (\%DD) ve belli bir derinlikte 1şının düzgünlüğünü ve simetrisini gösteren 1şın profil (IP) ölçümlerden oluşmaktadır. \%DD, belli bir derinlikte ölçülen radyasyon dozunun, maksimum doz derinliğinde ölçülen doza bölünmesiyle hesaplanır. Bu çalışmada, lineer hızlandırıcıda hasta öncesi başlangıç ölçümlerinde yapılabilecek $\leq 3 \mathrm{~mm}$ geometrik hatanın farklı alan boyutları için \%DD ve farklı derinlikteki IP parametreleri üzerindeki etkisini görmek amaçlanmıştır. Ayrıca yapılabilecek geometrik hatanın iyon odası farkına göre değişimi araştırılmıştır. Sonuçlar, ölçümler sırasında yapılabilecek $\leq 3 \mathrm{~mm}$ geometrik hatanın, özellikle yüzde derin doz parametreleri ve küçük alan simetrisi üzerinde etkisinin oldukça fazla olduğunu göstermektedir.

Anahtar kelimeler: Lineer hızlandırıcı, Radyoterapi, Yüzde derin doz, Işın profil

\section{The Effect of $\leq 3 \mathrm{~mm}$ Geometric Errors on the Percentage Depth Dose (PDD) and Beam Profile (BP) Parameters in Relative Dose Measurements Taken in the Linear Accelerator Device (Linac)}

\begin{abstract}
The modern linear accelerator (Linak) is a device that produces high-energy X-rays and electron beams for the treatment of cancer patients. The basis of radiation therapy is based on the interaction between substance and radiation. Therefore, the interaction between radiation and matter transforms the science of radiation physics into clinical treatment of cancer. In radiotherapy, the most basic relative evaluations for dosimetric measurements are; It consists of a percentage deep dose (DD\%) which shows the variation of the X-ray depending on the depth, and the beam profile (IP) measurements at which the flatness and symmetry of the beam can be calculated at a certain depth. DD\% is the ratio of the radiation dose measured at a certain depth to the dose measured at the maximum dose depth. In this study, it is aimed to investigate the effect of $\leq 3 \mathrm{~mm}$ geometric error that can be made in beam data measurements on DD\% for different field sizes and on IP parameters for different depths. In addition, the effect of geometric error on DD\% and IP parameters for different ion chambers was investigated. The results show that the $\leq 3 \mathrm{~mm}$ geometric error during the measurements has a significant effect especially on DD\% parameters and small field symmetry.
\end{abstract}


Key words: Linear accelerator, Radiotherapy, Percentage depth dose, Beam profile 1. Giriş

Modern lineer hızlandırıcı (Linak) cihazları, kanserli hastaların tedavisi için yüksek enerjili X-ışınları ve elektron demetleri üreten bir cihazdır. Radyasyon tedavisinin temeli madde ve radyasyon arasındaki etkileşime dayanır. $\mathrm{Bu}$ etkileşim sırasında iyonize radyasyon üretilir. Hücreler yeterince iyonlaşma elde ettiğinde, DNA zincirlerindeki kopmalar ile yok olurlar. Bu nedenle, radyasyon ve madde arasındaki etkileşim, radyasyon fiziği bilimini, kanserin klinik tedavisine dönüştürür [1]. Linak'ta, yüksek enerjili X-1şınları, dalga kılavuzunda hızlandırılmış elektronların ağır metallerden üretilmiş bir hedefe çarptırılmasıyla üretilir. Üretilen X-1şınları cihaz kafasında yer alan kolimatör sistemi ile farklı alan boyutlarında sınırlandırılabilmektedir. Işın kalitesi hedef malzemenin tasarımına bağlıdır. Tüm hızlandırıcılarda, enerji spektrumunu değiştirmek düzleştirici filtreler ile sağlanır. Bu etkinin büyüklüğü kullanılan malzemeye ve kalınlığına bağlıdır [2,3]. Bu faktörlere ek olarak, ikincil radyasyonların spektrumunu ve büyüklüğünü değiştiren kolimatör sisteminin tasarımı gibi başka faktörler de vardır [4]. Günümüzde, medikal fizik alanında var olan gelişmeler ile üç boyutlu radyasyon tedavisi (3DRT), yoğunluk ayarlı radyasyon tedavisi (YART), stereotaktik radyo cerrahi (SRC) gibi teknikler yaygin olarak kullanılmaktadır.

Radyasyon tedavisinin sonucu, geometrik ve dozimetrik ölçümlerin ve tedavi planlamasında kullanılan ışın verilerinin doğruluğu ile ilişkilidir. Bu veriler, Linak'ın ilk kullanıma alınması sırasında elde edilir ve klinik uygulamalar için standart veri olarak değerlendirilir. Cihaz, parametrelerinin değişmediğinden emin olmak için kalifiye bir fizikçi tarafından periyodik olarak doğrulanmalıdır [5]. Cihaz belli standartlarda geometrik limitler içinde yer aldığı araştırıldıktan sonra dozimetrik ölçümlere başlanır. Dozimetrik ölçümler için en temel rölatif ölçümler; X-ışınının derinliğe bağlı olarak değişimini gösteren yüzde derin doz (\%DD) ve belli bir derinlikte 1şının düzgünlüğünü, simetrisini ve 1şın penumbrasını gösteren 1şın profil (IP) parametrelerinden oluşmaktadır. \%DD, belli bir derinlikte ölçülen radyasyon dozunun, maksimum doz derinliğinde ölçülen doza bölünmesiyle hesaplanır [6].

Bu ölçümlerin, uluslararası pek çok protokolde hangi sınırlar içinde yer alması gerektiği raporlanmıştır. Çoğu protokolde uygulanan, kimi zaman kalite faktörü olarak da adlandırılan parametre, su fantomunda $200 \mathrm{~mm}$ derinlikteki iyon odası okumasının 100 mm derinlikteki okumaya oranıdır. $\mathrm{Bu}$ aslında doku fantom oranıdır $\left(\mathrm{DFO}_{20 / 10}\right)$ [7].

Ölçümlerde, $4 \times 4-40 \times 40 \mathrm{~cm}^{2}$ alanlar standart alanlar olarak bilinirken, $4 \mathrm{~cm}^{2}$ den küçük alanlar YART ve SRC gibi radyoterapi tekniklerinde kullanılır [8]. Küçük alanların var olduğu bu teknikler beraberinde çeşitli dozimetrik zorlukları getirmiştir. En önemlisi ölçümler sırasındaki detektöre bağlı yüklü parçacık dengesinin olmayışıdır [9]. Bu sorun için küçük hacimli detektörlerin kullanılması önerilmiştir [10].

Bu çalışmada, lineer hızlandırıcıda klinik kullanıma başlamadan önce alınan ölçümlerde yapılabilecek $\leq 3 \mathrm{~mm}$ geometrik hatanın farklı alan boyutları için \%DD ve farklı derinlikteki IP parametreleri üzerindeki etkisini görmek amaçlanmıştır. Çalışmada, limit hata değerinin $3 \mathrm{~mm}$ ve daha az seçilmesinin sebebi, görsel olarak ayırt edilemeyebilecek hataların dozimetrik sonuçlarını incelemektir. Ayrıca, geometrik hatanın iyon odası farkına göre değişimi araştırılmıştır. 


\section{Materyal ve Metot}

Çalışmada, tüm yüzde derin doz (\%DD) ve 1şın profil (IP) ölçümleri Elekta marka Synergy Platform model Lineer hizlandırıcı cihazında 6 MV foton enerjisi kullanılarak yapılmıştır. Ölçümlerde IBA marka su fantomu (IBA-Dosimetry, Schwarzenbruck, Germany Blue Phantom) kullanılmıştır. Kare alan boyutları 2, 3, 4, 5, 7 ve $10 \mathrm{~cm}^{2}$ için $0.04 \mathrm{cc}$ aktif hacme sahip IBA CC04 iyon odası kullanılmıştır. 5, 7, 10, 12, 15, 20, 25, 30 ve $40 \mathrm{~cm}^{2}$ için $0.13 \mathrm{cc}$ aktif hacme sahip IBA CC13 model iyon odası (IBADosimetry, Schwarzenbruck, Germany) kullanılmıştır. Ölçüm kurulumu Şekil 1'de gösterildiği gibi kaynak-yüzey uzaklığ 1 (KYU) $100 \mathrm{~cm}$ olacak şekilde ayarlanmıştır. Sekil 1'de DT, T derinliğinde absorbe edilen, DP ise sabit bir referans derinlikte $\left(\mathrm{d}_{\max }\right)$ absorbe edilen dozdur.

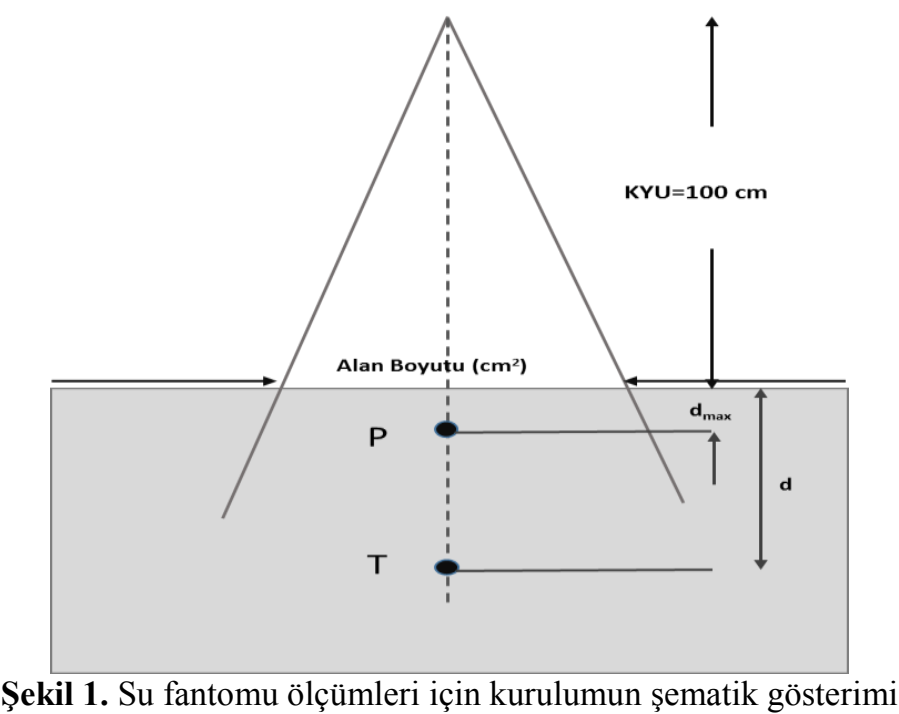

Tüm ölçümler için iki farklı ölçüm düzeneği hazırlanmıştır. Düzeneğe ait düzlem şeması Şekil 2'de görülmektedir. İlk düzenekte, iyon odası hem X hem de Y ekseninde alan merkezine yerleştirilirken $\mathrm{Z}$ ekseninde her bir iyon odasının kendi etkin noktası hesaplanarak merkez ayarlanmıştır (D6MV). İkinci düzenekte ise hem $\mathrm{X}$ hem $\mathrm{Y}$ ekseninde $\leq 3 \mathrm{~mm}$ hatalı yerleşim ile ve $Z$ ekseninde iyon odasının etkin noktası göz ardı edilip orta noktasına göre ayarlama yapılmıştır (Y6MV).

Yüzde Derin Doz değerlendirmesinde, tüm alan boyutları, maksimum doz derinliğinde 100 olacak şekilde normalize edilmiştir. Elde edilen grafiklerden , 200, 100 ve $50 \mathrm{~mm}$ derinlikteki yüzde derin dozlar (sırasıyla; $\mathrm{D}_{200}, \mathrm{D}_{100}$ ve $\mathrm{D}_{50}$ ), maksimum doz derinliği $\left(\mathrm{d}_{\max }\right)$ ve doku-fantom oranı $\left(\mathrm{DFO}_{20 / 10}\right)$ her iki düzenleme için (D6MV ve Y6MV) hem alan boyutu, hem de kullanılan iyon odası değişimine göre incelenmiştir. Işın Profil değerlendirilmesinde, alınan tüm profiller merkezi eksende 100 olacak şekilde normalize edilmiştir. Tüm alan boyutlarında, $\mathrm{d}_{\max }, 50$ ve $100 \mathrm{~mm}$ derinliklerde profiller alınmıştır. Profil eğrilerinden, alan simetri ve düzgünlük parametreleri her iki düzenleme için (D6MV ve Y6MV) hem alan boyutu hem de kullanılan iyon odasına bağlı olarak karşılaştırılmıştır. Ayrıca, aynı değişkenler için her bir profilin penumbra değerlendirmesi yapılmıştır. 


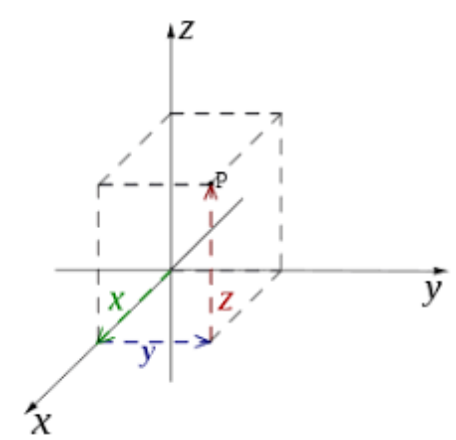

Şekil 2. Su fantomu ölçümleri için kurulum eksenlerinin şematik gösterimi.

Simetri (\%) hesaplamaları, nokta farkı prensibine göre hesaplanmıştır. Bu hesaba göre; düzleştirilmiş alan boyunca, merkez eksenden eşit uzaklıktaki grafiğin solundaki ve sağındaki noktalar arasındaki maksimum doz farkı, simetri olarak tanımlanmıştır.

Düzgünlük (\%), merkezde 100'e normalize edilmiş 1şıı profilinin maksimum ve minimum doz değişimine göre hesaplanmıştır. Penumbra $(\mathrm{mm})$ ise profilin sağında ve solunda \%20 ile \%80'lik dozların geçtiği mesafelerin farkları hesaplanarak bulunmuştur.

\section{Bulgular}

\subsection{Yüzde Derin Doz}

Kare alan boyutları 2, 3, 4, 5, 7 ve $10 \mathrm{~cm}^{2}$ için CC04 iyon odası ile doğru düzenlemede (D6MV) ve geometrik hata yapılarak hazırlanan düzenleme (Y6MV) için yüzde derin doz eğrileri oluşturulmuştur. Ayrıca, yukarıda bahsedilen ölçümler CC13 iyon odası için $5,7,10,12,15,20,25,30$ ve $40 \mathrm{~cm}^{2}$ alan boyutları için tekrarlanmış ve eğriler oluşturulmuştur. $\mathrm{Bu}$ grafikten elde edilen verilere göre 1şının giriciliği hakkında bazı parametrelere ulaşılmıştır. Tablo 1'de D6MV için, farklı alan boyutu ve iyon odasına bağlı olarak $\mathrm{D}_{200}, \mathrm{D}_{100}, \mathrm{D}_{50}, \mathrm{~d}_{\max }$ ve $\mathrm{DFO}_{20 / 10}$ parametrelerinin değişimi görülmektedir. Aynı parametrelerin değerlendirmesi Y6MV için Tablo 2'de bulunmaktadır.

Şekil 3 ve 4'de ise sırasıyla $\mathrm{D}_{50}$ ve $\mathrm{D}_{100}$ parametrelerinin alan boyutuna bağlı grafikleri her iki düzenleme (D6MV ve Y6MV) için görülmektedir.

$\mathrm{D}_{50 \mathrm{~mm}}$

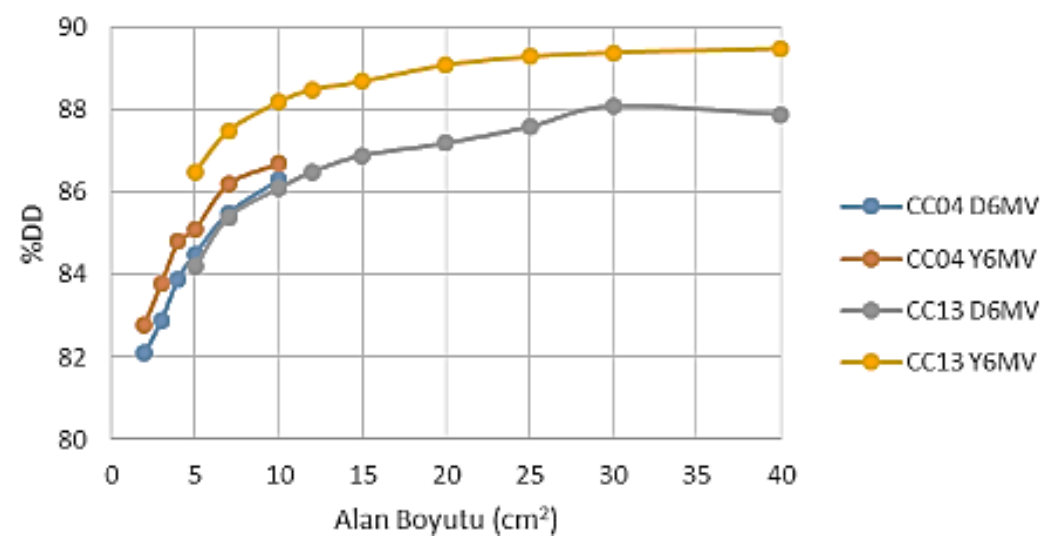

Şekil 3. Her iki düzenleme (D6MV ve Y6MV) için $\mathrm{D}_{50}$ parametresinin alan boyutuna bağlı grafiği. 


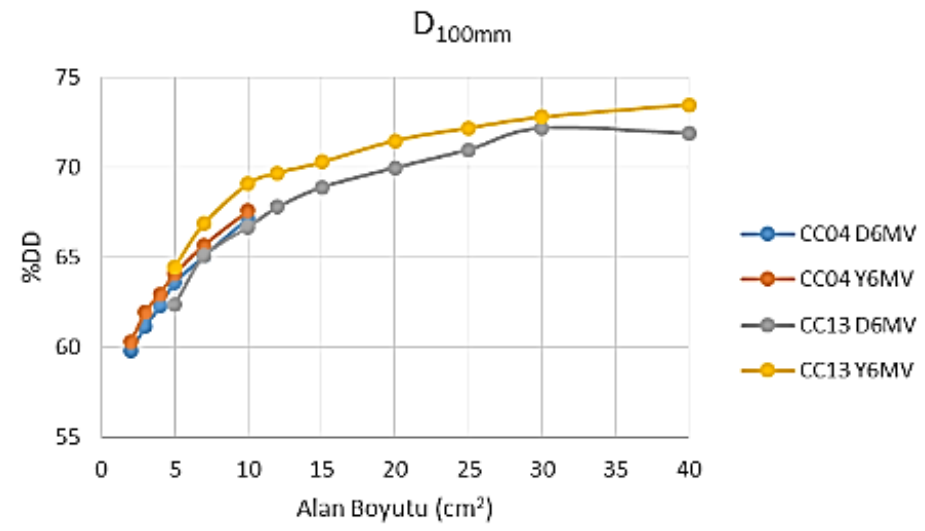

Şekil 4. Her iki düzenleme (D6MV ve Y6MV) için $D_{100}$ parametresinin alan boyutuna bağlı grafiği.

Tablo 1. D6MV ölçüm düzenlemesi için farklı alan boyutu ve iyon odasına göre \%DD parametreleri

\begin{tabular}{|c|c|c|c|c|c|c|c|c|c|c|c|c|c|}
\hline & & \multicolumn{12}{|c|}{ Alan boyutu $\left(\mathrm{cm}^{2}\right)$} \\
\hline $\begin{array}{l}\text { İyon } \\
\text { Odası } \\
\end{array}$ & $\begin{array}{c}\text { \%DD } \\
\text { parametreleri }\end{array}$ & 2 & 3 & 4 & 5 & 7 & 10 & 12 & 15 & 20 & 25 & 30 & 40 \\
\hline \multirow{5}{*}{$\operatorname{cc04}$} & $\mathrm{D}_{50}$ & 82.1 & 82.9 & 83.9 & 84.5 & 85.5 & 86.3 & & & & & & \\
\hline & $\mathrm{D}_{100}$ & 59.8 & 61.2 & 62.3 & 63.6 & 65.1 & 67.2 & & & & & & \\
\hline & $\mathrm{D}_{200}$ & 32.5 & 33.4 & 34.1 & 35.5 & 37.0 & 39.2 & & & & & & \\
\hline & $\mathrm{d}_{\max }$ & 13.7 & 15.7 & 14.7 & 15.7 & 15.7 & 14.7 & & & & & & \\
\hline & $\mathrm{DFO}_{20 / 10}$ & 0.63 & 0.63 & 0.63 & 0.65 & 0.66 & 0.68 & & & & & & \\
\hline \multirow{5}{*}{$\operatorname{cc} 13$} & $\mathrm{D}_{50}$ & & & & 84.2 & 85.4 & 86.1 & 86.5 & 86.9 & 87.2 & 87.6 & 88.1 & 87.9 \\
\hline & $\mathrm{D}_{100}$ & & & & 62.4 & 65.1 & 66.7 & 67.8 & 68.9 & 70.0 & 71.0 & 72.2 & 71.9 \\
\hline & $\mathrm{D}_{200}$ & & & & 34.6 & 37.0 & 38.7 & 40.2 & 41.6 & 43.3 & 44.6 & 46.4 & 46.7 \\
\hline & $\mathrm{d}_{\max }$ & & & & 16.7 & 14.7 & 14.7 & 15.7 & 12.7 & 12.7 & 12.7 & 12.7 & 11.7 \\
\hline & $\mathrm{DFO}_{20 / 10}$ & & & & 0.64 & 0.66 & 0.68 & 0.69 & 0.70 & 0.72 & 0.74 & 0.76 & 0.76 \\
\hline
\end{tabular}

Tablo 2. Y6MV ölçüm düzenlemesi için farklı alan boyutu ve iyon odasına göre \%DD parametreleri

\begin{tabular}{cccccccccccccc}
\hline & & \multicolumn{10}{c}{ Alan boyutu $\left(\mathrm{cm}^{2}\right)$} \\
\hline $\begin{array}{c}\text { İyon } \\
\text { Odası }\end{array}$ & $\begin{array}{c}\text { \%DD } \\
\text { parametreleri }\end{array}$ & $\mathbf{2}$ & $\mathbf{3}$ & $\mathbf{4}$ & $\mathbf{5}$ & $\mathbf{7}$ & $\mathbf{1 0}$ & $\mathbf{1 2}$ & $\mathbf{1 5}$ & $\mathbf{2 0}$ & $\mathbf{2 5}$ & $\mathbf{3 0}$ & $\mathbf{4 0}$ \\
\hline \multirow{4}{*}{$\operatorname{cc} 04$} & $\mathrm{D}_{50}$ & 82.8 & 83.8 & 84.8 & 85.1 & 86.2 & 86.7 & & & & & & \\
& $\mathrm{D}_{100}$ & 59.8 & 61.2 & 62.3 & 63.6 & 65.1 & 67.2 & & & & & & \\
& $\mathrm{D}_{200}$ & 33.3 & 33.9 & 34.7 & 35.7 & 37.4 & 39.6 & & & & & & \\
& $\mathrm{~d}_{\max }$ & 14.7 & 15.7 & 15.7 & 15.7 & 16.8 & 15.7 & & & & & & \\
& $\mathrm{DFO}_{20 / 10}$ & 0.64 & 0.63 & 0.64 & 0.65 & 0.66 & 0.68 & & & & & & \\
& $\mathrm{D}_{50}$ & & & & 86.5 & 87.5 & 88.2 & 88.5 & 88.7 & 89.1 & 89.3 & 89.4 & 89.5 \\
& $\mathrm{D}_{100}$ & & & & 64.5 & 66.9 & 69.1 & 69.7 & 70.3 & 71.5 & 72.2 & 72.8 & 73.5 \\
$\operatorname{cc} 13$ & $\mathrm{D}_{200}$ & & & & 35.5 & 38.0 & 40.8 & 41.2 & 42.5 & 44.3 & 45.6 & 46.4 & 47.4 \\
& $\mathrm{~d}_{\max }$ & & & & 18.7 & 18.7 & 17.7 & 17.7 & 17.7 & 17.7 & 16.7 & 16.7 & 16.7 \\
& $\mathrm{DFO}_{20 / 10}$ & & & & 0.64 & 0.66 & 0.69 & 0.69 & 0.71 & 0.73 & 0.74 & 0.75 & 0.76 \\
\hline
\end{tabular}

\subsection{Işın Profilleri}

CC04 iyon odası ile alınan ölçümler için, Tablo 3'de 2, 3, 4, 5 ve $10 \mathrm{~cm}^{2}$ alan boyutlarında, $\mathrm{d}_{\max }, 50$ ve $100 \mathrm{~mm}$ derinliklerdeki simetri, düzgünlük ve penumbra değerlerinin D6MV ve Y6MV'ye göre değişimi yer almaktadır. Tablo 4'de ise CC13 iyon odası ile alınan ölçümler için, aynı derinliklerde10, 15, 20 ve $30 \mathrm{~cm}^{2}$ kare alan boyutlarındaki parametre değerleri görülmektedir. 
Tablo 3. CC04 iyon odası için her iki düzenlemede farklı alan boyutu ve derinlikler için IP parametreleri

\begin{tabular}{ccccccccccccccc}
\hline & \multicolumn{1}{c}{} & $\mathbf{2}$ & \multicolumn{10}{c}{ Alan Boyutu $\left(\mathbf{c m}^{\mathbf{2}}\right)$} \\
\hline & & \multicolumn{10}{c}{$\mathbf{c}$ Derinlik (mm) } \\
\hline $\begin{array}{c}\text { IP } \\
\text { parametreleri }\end{array}$ & & $\mathbf{d}_{\text {max }}$ & $\mathbf{5 0}$ & $\mathbf{1 0 0}$ & $\mathbf{d}_{\text {max }}$ & $\mathbf{5 0}$ & $\mathbf{1 0 0}$ & $\mathbf{d}_{\text {max }}$ & $\mathbf{5 0}$ & $\mathbf{1 0 0}$ & $\mathbf{d}_{\text {max }}$ & $\mathbf{5 0}$ & $\mathbf{1 0 0}$ \\
\hline Simetri & D6MV & 2.2 & 2.1 & 1.2 & 0.8 & 1.4 & 1.5 & 0.9 & 0.7 & 0.7 & 0.7 & 0.9 & 1.0 \\
(\%) & Y6MV & 18.3 & 15.9 & 18.2 & 9.6 & 9.5 & 10.3 & 2.8 & 3.4 & 3.4 & 1.1 & 1.1 & 0.7 \\
Düzgünlük & D6MV & 11.0 & 11.5 & 11.1 & 5.4 & 6.5 & 6.6 & 2.3 & 2.9 & 2.9 & 1.1 & 1.1 & 1.9 \\
(\%) & Y6MV & 10.9 & 11.5 & 11.3 & 5.7 & 6.8 & 6.5 & 2.5 & 2.9 & 3.0 & 1.2 & 1.2 & 1.9 \\
Penumbra & D6MV & 3.8 & 4.1 & 4.5 & 4.3 & 4.4 & 4.5 & 4.4 & 4.4 & 5.0 & 4.5 & 4.9 & 5.6 \\
(mm) & Y6MV & 3.9 & 4.1 & 4.5 & 4.3 & 4.4 & 4.6 & 4.4 & 4.6 & 5.0 & 4.6 & 5.0 & 5.7 \\
\hline
\end{tabular}

Tablo 4. CC13 iyon odası için her iki düzenlemede farklı alan boyutu ve derinlikler için IP parametreleri

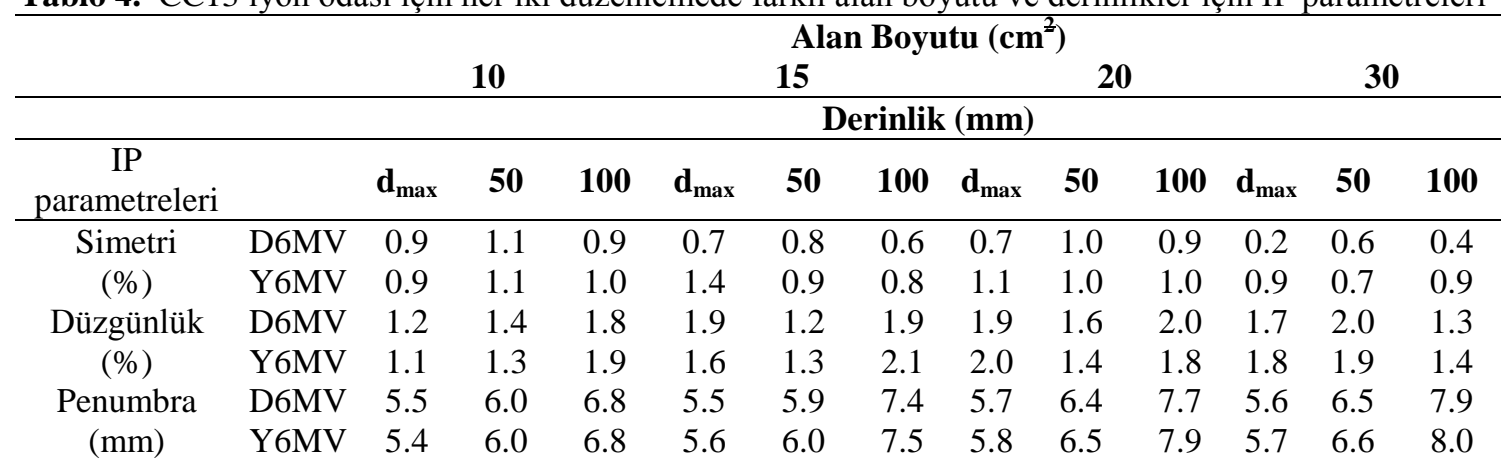

\section{Sonuç ve Yorum}

Klinik kullanım için bir Linak'ı çalıştırma süreci, dozimetrik parametrelerin kapsamlı ölçümlerini içermektedir. Linak'ın kullanıma başlama öncesi, hasta tedavisi için kullanılacak eksiksiz bir veri setinin elde edildiği süreçtir. Farklı alan boyutlarında, yüzde derin doz (\%DD), Işın Profilleri (IP) ve doz verim ölçümlerini içeren temel parametreler, bu süreçte gerekli olan önemli dozimetrik verilerdir [11]. Radyasyon tedavisinin sonucu, tedavi planlaması sürecinde kullanılan ışın verilerinin doğruluğuna bağlı değişmektedir. Bu nedenle, tedavi amaçlı bir Linak sistemini çalıştırmak için, yüzde derin dozların doğru olarak ölçülmesine ihtiyaç vardır. Çoğunlukla, ölçülen sonuçlar Uluslararası Elektroteknik Komisyonu (IEC 60976) protokolü [12] izlenerek doğrulanır. Kalite güvencesi için ise İngiliz Radyoloji Dergisi 25 [13], Amerikan Tıpta Fizikçiler Derneği - Görev Grubu- 40 (AAPM TG 40) [14] takip edilmektedir.

YART alanlarının doğrulanması için ölçüm detektörleri hakkında birçok çalışma olmasına rağmen [15-17], tedavilere başlamadan önceki temel veri toplama aşamasında dozimetriye daha az dikkat edilmiştir $[18,19]$. Çalışmada veri toplama aşamasında yapılabilecek yaklaşık $3 \mathrm{~mm}$ geometrik hataların dozimetrik yansıması aşağıda tartışılmıştır.

Yüzde derin doz: Merkezi eksen doz dağılımını karakterize etmek için, tüm derinliklerdeki dozun, referans derinlikteki doza normalize edilmesi gerekir. IEC 60731 protokolüne göre [20] $6 \mathrm{MV}$ foton enerjisi için maksimum doz derinliği $1.5 \pm 0.2 \mathrm{~cm}$ olmadır. Çalışmada, $d_{\max }$ derinliği CC13 ile ölçüm alınan Y6MV ölçümünde limit dışında bulunmuştur $(1.8 \mathrm{~cm})$. Ayrıca aynı protokole göre $100 \mathrm{~mm}$ 'de $\%$ doz değeri \% $67.1 \pm 1.5$ olarak raporlanmıştır. Bizim çalışmamızda, $\mathrm{D}_{100} \mathrm{CC} 13$ ile alınan Y6MV'de limit dişında bulunmuştur $(\% 69.1)$. $\mathrm{DFO}_{20 / 10}$ değerinin ise $0.676 \pm 0.009$ olması 
beklenmektedir. Bizim çalışmamızda bu değer, CC13 ile alınan Y6MV'de limit dışında yer almaktadir (0.690).

Küçük alanlarda, bir noktadaki derin dozun, birincil radyasyonun, yani ortamda etkileşmeye girmeyen fotonların bir sonucu olduğu varsayılabilir. $\mathrm{Bu}$ durumda, saçılan fotonların derin doza katkısı ihmal edilebilir derecede küçük veya sıfırdır [21]. Bu sebeple $5 \mathrm{~cm}^{2}$ den daha küçük alanlarda aktif hacmi daha küçük olan CC04 gibi detektörler ile alınan ölçümlerin daha doğru olduğu bilinmektedir. $10 \mathrm{~cm}^{2}$ ve daha büyük alanlarda ise CC13 gibi aktif hacmi daha fazla detektörlerle alınan ölçümler daha doğru sonuçlara ulaştırmaktadır. Fakat alan büyüklüğü arttıkça, saçılan radyasyonun absorbe edilen doza katkısı da artar. Saçılan dozdaki bu artış, $\mathrm{d}_{\max }$ derinliğinden daha büyük derinliklerde olduğundan, artan alan boyutu ile \%DD artar [21]. Bizim çalışmamızda daha derine inildikçe $5 \mathrm{~cm}^{2}$ ile $10 \mathrm{~cm}^{2}$ arasındaki en büyük doz farkı 200 mm derinlikte bulunmuştur (\%17.1).

TRS 398 [7] rehberliğinde Elekta cihazı için alınan ölçümlere göre değerlendirmelerde $\mathrm{DFO}_{20 / 10} 10 \mathrm{~cm}^{2}$ için hesaplamış ve 0.678 bulunmuştur. Bizim çalışmamızda ise D6MV için 0.679 iken Y6MV için 0.692 olarak bulunmuştur.

Çalışma sonuçlarına göre, geometrik hata ile alınan ölçümlerde, eğer ölçüm şartları sorgulanmadan ışın kalitesi için yorum yapılırsa, cihazda enerji azaltmaya yönelik değişime sebep olabilir ki bu çok önemli bir değişim olacaktır.

Işın profili: Düzgünlük değerinin, $100 \mathrm{~mm}$ derinlik ve $10 \times 10 \mathrm{~cm}^{2}$ alanda $\% 3$ sınırları içinde yer alması gerekmektedir [22]. Çalışmada, $10 \times 10 \mathrm{~cm}^{2}$ alan boyutu ve $100 \mathrm{~mm}$ derinlikte hem D6MV hem de Y6MV için değerler sırasıyla 1.8 ve 1.9 olarak bulunmuştur. Ayrıca, alan boyutu arttıkça 1şın alan düzgünlüğü artmaktadır. 5x5 $\mathrm{cm}^{2}$ 'den büyük alanların hepsinde düzgünlük limitler içinde yer almaktadır.

Simetri değerinin, $100 \mathrm{~mm}$ derinlik ve $10 \times 10 \mathrm{~cm}^{2}$ alanda $\% 3$ sınırları içinde yer alması gerekmektedir [20]. Çalışmada, 10x10 $\mathrm{cm}^{2}$ alan boyutu ve $100 \mathrm{~mm}$ derinlikte hem D6MV hem de Y6MV için değerler sirasıyla 0.9 ve 1.0 olarak bulunmuştur. Simetri değerlerinin karşılaştırılmasında en büyük fark Y6MV için $2 \times 2 \mathrm{~cm}^{2}$ alanda $\mathrm{d}_{\max }$ derinliğinde görülmüştür (\%18.2). D6MV için tüm alan boyutlarında, her iki iyon odasında ve tüm derinliklerde değerler \%3'den küçük bulunmuştur. Fakat Y6MV için, $5 \times 5 \mathrm{~cm}^{2}$ 'den küçük alanlarda tüm değerler \%3'den büyük ve limit dişı bulunmuştur.

Penumbra, $15 \times 15 \mathrm{~cm}^{2}$, den küçük alanlar için 7 mm'den küçük ve $15 \times 15 \mathrm{~cm}^{2}$, den büyük alanlarda 8 mm'den küçük olmalıdır [22]. D6MV ve Y6MV ile ölçüm sonuçlarında, penumbra değerleri yaklaşık olarak aynıdır. Bazı ölçümlerde limit dışı olmayan fakat iki detektör ölçümü arasında küçük farklar tespit edilmiştir. Bunların nedeninin bir kısmının elektrometreden kaynaklı elektriksel gürültünün grafiğe yansıması olduğu ve ayrıca yüzeye yakın ölçümlerde detektörün hareketine bağlı olarak suyun dalgalanması ile derinliğin değişmesi neticesinde bu farkın ortaya çıktığını düşünülmektedir. Mevcut çalışmalardan açıkça anlaşılacağı gibi, YART öncesi, uygun bir yüksek çözünürlüklü detektörler ile penumbraların kapsamlı değerlendirmesi gerekmektedir. Tipik olarak ışın verisi toplamada kullanılan $0.1-0.2$ cc hacimdeki standart iyon odaları, ölçülen penumbrayı spesifik ölçüm koşullarına bağlı olarak yaklaşık 0.2 - $0.3 \mathrm{~cm}$ arttırmaktadır [23]. 
Çalışmada, CC13 ile yapılan ölçümlerde penumbra değerlerinde artış görülmüştür. Bunun nedenin, iyon odası hacminden dolayı radyasyon alanında oluşan pertürbasyon olduğu bilinmektedir. Ayrıca içerisinde hava olduğundan radyasyon enerjisini dokuya göre daha uzağa aktarmaktadır. Bu durum penumbra bölgesinde genişlemeye yol açmaktadır. Çalışmada, en büyük fark ise $5 \times 5 \mathrm{~cm}^{2}$ alan ve $50 \mathrm{~mm}$ derinlikte bulunmuştur $(1.3 \mathrm{~mm})$. Ayrıca, tüm alan boyutları, derinlikler ve iyon odaları için hem D6MV hem de Y6MV 'de penumbra değerleri limit içindedir.

Lineer hızlandırıcılarda, klinik foton 1şınlarının dozimetrik özelliklerini belirleyen radyasyon kaynakları şunlardır. Doğrudan radyasyon (hedefte oluşan ve herhangi bir ara etkileşim olmaksızın hastaya ulaşan fotonlar), dolaylı radyasyon (düzleştirici filtre, kolimatörler veya tedavi kafasındaki diğer yapılar ile etkileşim/saçılma öyküsü olan fotonlar) ve kontaminant elektronlar/ pozitronlardır (tedavi kafası veya hava sütunu ile etkileşimlerden salınan ikincil elektronlar ve pozitronlar). Tüm bu etkileşmeler, merkezi eksende yer almayan, hatalı yerleştirilen ölçüm düzenekleri için farklı katkılar sağlayacaktır. Aynı zamanda ölçümde kullanılan detektörlerin aktif hacmi özellikle küçük alanlarda önemli bir kriterdir.

Tüm protokoller tam anlamıyla uygulansa da en önemli faktör uygulamayı gerçekleştiren fizikçinin deneyimi ve dikkatidir. Ölçümler sırasında gözden kaçabilecek yaklaşık $3 \mathrm{~mm}$ hatanın, özellikle yüzde derin doz ve küçük alan simetrisi üzerindeki etkisi oldukça fazladır. Fakat asıl değerlendirme, hasta tedavisi öncesi yapılan kalite kontrollerde hastaya nasıl yansıdığını bularak yapılmalıdır. Çalışmanın ikinci adımında, geometrik hata barındıran Linak ölçümlerinin hasta tedavi planları üzerine etkisi araştırılacaktır.

\section{Kaynakça}

[1] J. Horton, Handbook of Radiation Therapy Physics, Englewood Cliffs, NJ: Prentice-Hall, 1987, pp. 200-1100.

[2] M. Hossain, Y. Xiao, and M. S. Huq, "An investigation of a model of percentage depth dose for irregularly shaped fields," International Journal of Cancer, 96, 140-145, 2001.

[3] M. J. Price, K. R. Hogstrom, J. A. Antolak, A. White, D. Charles, and R. A. Boyd, "Calculating percent depth dose with the electron pencil-beam redefinition algorithm," Journal of Applied Clinical Medical Physics, 2, 61-76, 2010.

[4] K. Ślosarek, and A. Rembielak, "Comparison of Percent Depth Doses for Various Linear Accelerators," Med. Physics, 11, 39-50, 2005.

[5] T. G. Kutcher, L. Chair, M. Coia, W. F. Gillin, S. Hanson, R. J. Leibel, J. R. Morton, J. Palta, L. E. Purdy, G. K. Reinstein, M. Svensson, and L. Wingfield, "Comprehensive QA for Radiation Oncology," Med. Phys., 21, 581-618, 1994.

[6] C. Packard, "Calculation of percentage depth dose. Radiology," Radiology Society of North America. 82nd scientific assembly and annual meeting, Chicago, Illiois. 2009, 130 (5): 44 - 48

[7] IAEA (International Atomic Energy Agency), "Absorbed Dose Determination in External Beam Radiotherapy: An International Code of Practice for Dosimetry Based on Standards of Absorbed Dose to Water," TRS-398, 11, 157-164, 2004.

[8] I. J. Dasa, G. X. Ding, and A. Ahnesjö, "Small fields: Nonequilibrium radiation dosimetry," Med. Phys. 35, 206-216, 2008.

[9] E. Nahum, "Perturbation effects in dosimetry. Kilovoltage x-rays and electrons," Phys. Med. Biol. 41,1531-1580, 1996.

[10] A. Sauer, and J. Wilbert, "Measurement of output factors for small photon beams," Med. Physics, 34,1983-1988, 2007.

[11] R. N. Sruti, M. M. Islam, M. M. Rana, M. H. Bhuiyan, K. A. Khan, M. K. Newaz, and M. S. Ahmed, "Measurement of Percentage Depth Dose of a Linear Accelerator for $6 \mathrm{MV}$ and $10 \mathrm{MV}$ Photon Energies," Nuclear Science and applications 24, 29-32, 2015.

[12] IEC (International Electrotechnical Commission), "Medical electrical equipment-Medical electron accelarators-Functional performance characteristics," 2007, Standard IEC-60976, IEC, Geneva. 
[13] M. J. Day and E. G. Aird, “Central Axis Depth Dose Data for Use in Radiotherapy,” BJR, Vol. Sup. 25, 90s, 1996.

[14] American Association of Physicists in Medicine(AAPM), "Comprehensive Qa for Radiation Oncology," 1994, Task Group 40, AAPM,USA.

[15] C. Martens, D. Wagter, and W. Neve, "The value of the PinPoint ion chamber for characterization of small field segments used in intensity modulated radiotherapy," Phys. Med. Biol. 45, 2519-2530, 2000.

[16] S. G. Lu, Y. C. Ahn, S. J. Huh, and I. J. Yeo, "Film dosimetry for intensity modulated radiation therapy: Dosimetric evaluation," Med. Phys. 29, 351-355, 2002.

[17] L. Childress, L. Dong, and I. I. Rosen, "Rapid radiographic film calibration for IMRT verification using automated MLC fields," Med. Phys. 29, 2384-2390, 2002.

[18] V. Esch, J. Bohsung, P. Sorvari, M. Tenhunen, M. Paiusco, M. Lori, P. Engstrom, H. Nystrom, and D. P. Huyskens, "Acceptance tests and quality control (QC) procedures for the clinical implementation of intensity modulated radiotherapy (IMRT) using inverse planning and the sliding window technique: Experience from five radiotherapy departments," Radiother. Oncol. 65, 53-70, 2002.

[19] W. U. Laub, and T. Wong, "The volume effect of detectors in the dosimetry of small fields used in IMRT," Med. Phys. 30, 341-347, 2003.

[20] IEC (International Electrotechnical Commission), "Dosimeters With Ionization Chambers As Used in Radiotherapy," Medical Electrical Equipment, 1997, Standard IEC-60731, IEC, Geneva.

[21] F. M. Khan. The Physics of Radiation Therapy. New York: Springer 3rd ed.,2003, pp. 200-223,

[22] S. K. Sahoo, A. K. Rath, R. N. Mukharjee, and B. Mallick "Commissioning of a Modern LINAC for Clinical Treatment and Material Research," International Journal of Trends in Interdisciplinary Studies 1,10, 2012,

[23] F. G. Vicente, J. M. Delgado, and M. Peraza, "Experimental determination of the convolution kernel for the study of the spatial response of a detector," Med. Phys. 25, 202-207, 1998. 